\title{
Comparing the Behavioral Patterns and Psychological Characteristics of Web Board Gamers and Gamblers
}

\author{
Jiwon Han, Yeseul Seo, Choognmeong Lee, and Doug Hyun Han $\bowtie$ \\ Department of Psychiatry, Chung Ang University Hospital, Seoul, Republic of Korea
}

\begin{abstract}
Objective In Korea, online board games, such as "flower cards," are played using virtual money. In contrast, Internet-based gambling (ibGambling) concerns the use of real money to gamble online. We hypothesized that online board gamers using virtual money show less risky behaviors than do gamblers who use real money, and that, in regard to psychological aspects, online board gamers are less depressed and more introverted than online gamblers are.

Methods For this study, 100 online board gamers, 100 ibGamblers, 100 offline gamblers (offGamblers), and 100 age- and sex-matched healthy controls were recruited by an online research company. Gambling behavior and self-efficacy were assessed using the Korean Gambling Behavior Scale-high/low factors (KGBS-H/L) and the Gambling Abstinence Self-efficacy Scale (GASS). Additionally, introversion, depression, and mania tendency were assessed.

Results Online board gamers had good intentions gaming, as evidenced by their higher KGBS-L scores than ibGamblers and offGamblers, and they showed less risky behaviors, as evidenced by their lower KGBS-H scores than offGamblers. Additionally, online board gamers were less introverted than ibGamblers and less depressed than offGamblers.

Conclusion Online board gaming could be a gateway to the world of gambling (ibGambling or OffGambling). However, the higher tendency of online board gamers to engage in good intentioned gaming could help prevent online board gaming from progressing to online or offline gambling.

Psychiatry Investig 2018;15(12):1181-1187
\end{abstract}

Key Words Online board game, Gambling, Gambling behavioral scale.

\section{INTRODUCTION}

Online board games are real-time board games played through a web browser. ${ }^{1} \mathrm{~A}$ board game is classically defined as a game that is played on a board, with well-known examples being chess, backgammon, and monopoly; additionally, some board games are played using dice or poker cards. In Korea, a card game called "flower cards" (or "go-stop") is popular, and is played with a deck of Korean hwatu (flower cards). It accommodates one to four players, and it is somewhat similar to poker. Recently, flower cards have become extremely popular among players of online board games. While playing flower cards online, players use virtual money (i.e., not real money), which can be purchased on the websites hosting the

Received: June 17,2018 Revised: August 18, 2018 Accepted: October 22, 2018

$\square$ Correspondence: Doug Hyun Han, MD, PhD

Department of Psychiatry, Chung-Ang University, 84 Heukseok-ro, Dongjakgu, Seoul 06974, Republic of Korea

Tel: +82-2-6299-3132, Fax: +82-2-813-5387, E-mail: hduk70@gmail.com

(a) This is an Open Access article distributed under the terms of the Creative Commons Attribution Non-Commercial License (https://creativecommons.org/licenses/by$\mathrm{nc} / 4.0$ ) which permits unrestricted non-commercial use, distribution, and reproduction in any medium, provided the original work is properly cited. game. The Korean government has strictly limited the amount of virtual money (worth up to $\$ 500$ a month) users can purchase for playing online board games to better regulate the use of virtual money across the country. Many users who play flower cards online also enjoy playing poker and/or monopoly online. Moreover, in a small number of cases, online board gamers have illegally converted virtual money into real money through illegal websites.

Internet-based gambling (ibGambling) is a type of gambling (through poker, black jack, flower cards, etc.) in which real money is used online (typically through credit card transactions). In Korea, online gambling is illegal; however, it is very common for such gamblers to fund their illegal gambling through illegal transactions. In ibGambling, Korean gamblers access illegal gambling sites and bet real money using their personal computers in their homes. Online poker differs greatly from the offline version, as it allows individuals to play at home, affords a private playing environment and the freedom to smoke, does not require face-to-face interaction, and involves little verbal communication and fewer consequences regarding a lack of emotional control. ${ }^{2}$ However, the use of digital 
money is thought to increase the frequency of gambling and, concurrently, losses, as the players feel that they are not spending real money. ${ }^{3,4}$ In an online survey of 10,838 Internet gamblers, Gainsbury et al. ${ }^{5}$ reported that online poker players show a greater tendency to "chase their losses" (i.e., seek to recoup lost bets by increasing their subsequent bets) than casino gamblers do. Additionally, chasing losses was determined to be associated with irrational beliefs regarding gambling, as well as with greater expenditure of time and money. ${ }^{5}$ In a review of online poker, Moreau et al. ${ }^{6}$ reported that predictive factors for excessive online poker playing are stress, internal attribution, dissociation, boredom, negative emotions, irrational beliefs, anxiety, and impulsivity.

In gambling studies, more risky behavioral patterns have been found to be associated with greater expenditure of time and money, higher bets, and an inability to stop gambling. ${ }^{5-8}$ Moreover, pathological gambling behaviors have been reported to be associated with other psychopathologies such as depression and anxiety. ${ }^{9}$ Internet use is also frequently reported to be associated with depressive symptoms and introverted personalities, ${ }^{10}$ evidenced by a study of 49,609 university students, which revealed the presence of these characteristics among heavy Internet users. ${ }^{10,11}$

\section{Hypothesis}

We hypothesized that online board gamers using cybermoney exhibit less risky behaviors than gamblers do, and that, in terms of psychological aspects, online board gamers would be less depressed and introverted than gamblers.

\section{METHODS}

\section{Participant recruitment}

Between April 2 and 11, 2018, an invitation e-mail to participate in the current study was sent to 200,799 individuals aged 20 years and older, who were registered with an online research company (Embrain ${ }^{\circledR}$, Seoul, Korea). Participants who did not respond within three days or who started but failed to complete the survey were sent a reminder e-mail. If an individual accidentally completed the survey twice, the second survey was excluded. Participants were compensated \$20 when they completed the survey. By the end of the data collection period, 7,034 individuals had opened the e-mail; of these, 5,754 began the survey and 480 completed it. Of the 480 respondents (123 online board game users, 120 ibGamblers, 118 offline gamblers (offGamblers), and 119 healthy comparison subjects) who completed the survey, data for 400 participants (100 online board game users, 100 ibGamblers, 100 offline gamblers, and 100 healthy comparison subjects) were randomly gathered (Figure 1). The inclusion criteria for the online board

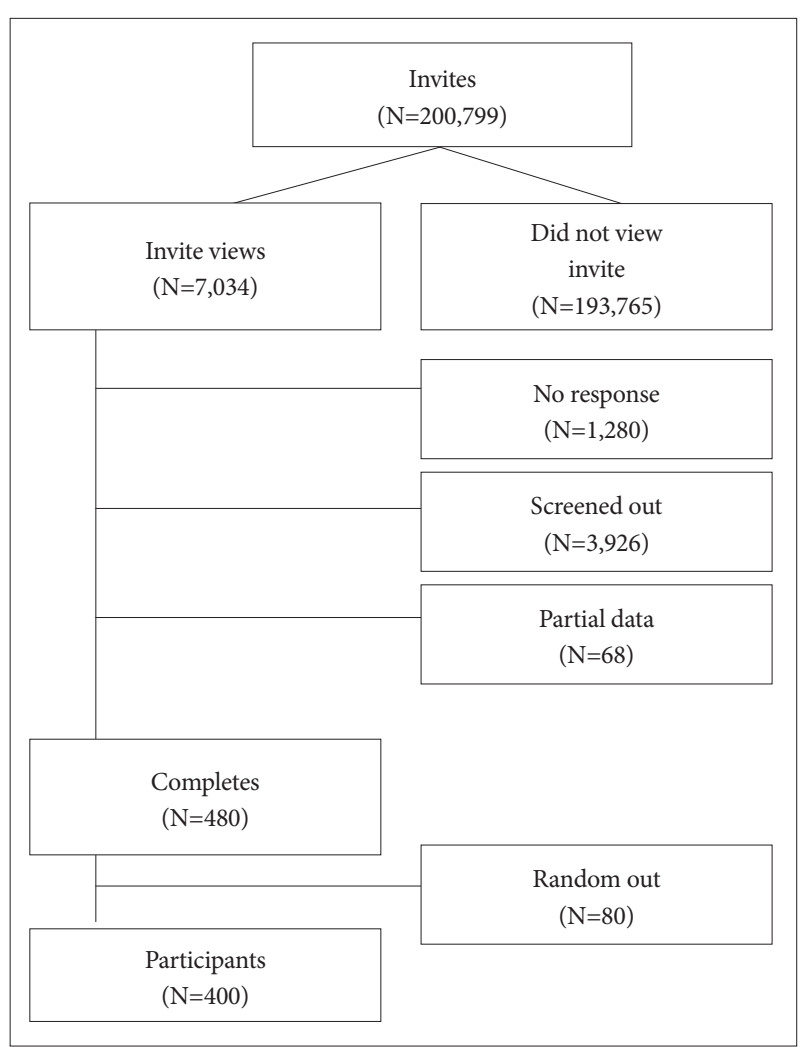

Figure 1. Process of recruiting participants.

gamer group were as follows: 1) aged 20 years or over; 2) engagement with an online board game (i.e., flower cards, poker, Texas hold'em) more than four days/week, with over one year's experience of betting on a legal site using virtual money; and 3 ) the presence of at least one of the following symptoms: anxiety, agitation, anger when ending an online board game, continually increasing bets, and a failure to stop gaming. The inclusion criteria for the ibGambling group were as follows: 1 ) aged 20 years or over; 2 ) engagement with ibGambling (i.e., flower cards, poker, Texas holdem) more than four days/week, with over one year's experience using credit cards on illegal sites to bet real money; and 3) the presence of at least one of the following symptoms: anxiety, agitation, anger when stopping gambling, continually increasing bets, and failure to stop gambling. The inclusion criteria for the offGambling group were as follows: 1 ) aged 20 years or over; 2 ) engagement with casino gambling (poker, slot machine, black jack) over one day/ month, with over one year's experience of casino betting; and 3 ) the presence of at least one of the following symptoms: anxiety, agitation, anger when stopping gambling, continually increasing bets, and a failure to stop gambling.

All participants signed the written informed consent form, and the study was approved by the Chung Ang University School of Medicine Research Ethics Committee IRB (1041078201802-HRSB-0260-01). 


\section{Assessment scales}

The Korean Gambling Behavior Scale (KGBS) consists of 10 items concerning low factors (KGBS-L) and 10 items concerning high factors (KGBS-H), and the field version was developed by the Korean National Gaming Control Commission. ${ }^{12,13}$ Using a four-point Likert scale ranging from 0 ("never") to 3 ("very much agree"), the KGBS-L assesses positive functions associated with gambling and disinterest in gambling, while the KGBS-H assesses the negative functions associated with gambling and high-risk behaviors in gambling. The KGBS has a Cronbach's $\alpha$ of $0.90-0.91 .^{12,13}$

The Gambling Abstinence Self-efficacy Scale (GASS) focuses on individuals seeking to quit gambling, assessing their confidence regarding their ability to abstain from gambling. ${ }^{14}$ It consists of 21 items that are scored using a six-point Likert scale ranging from 0 ("no confidence") to 5 ("very confident"). It has good internal (Cronbach $\alpha=0.93$ ) and retest (intraclass correlation $=0.86$ ) reliability. ${ }^{14}$

To assess introverted temperament, 32 social introversion questions were extracted from the Minnesota Multiphase Personality Inventory-2 (MMPI-2). Additionally, 17 questions for assessing "mania" were also extracted from the MMPI-2. The participants were asked to answer "yes" or "no" in response to all items.

The Center for Epidemiologic Studies-Depression Scale (CESD), a widely used self-report scale designed to assess depressive symptoms in the general population. ${ }^{15,16}$ CES-D scores can range from 0 to 60 , with a score of 16 or more being accepted as an indicator of depressive symptoms ${ }^{17}$ and a score of 24 or more suggestive of severe depressive symptoms. ${ }^{18}$

\section{Statistical analysis}

The demographic characteristics of all participants were analyzed using a one-way analysis of variance (ANOVA) and chi-square tests. Gambling tendency, assessed through the GASS and KGBS-H/L, and psychological symptoms, including introversion, mania tendency, and depression, were analyzed using an ANOVA. The correlations between scores on the KGBS-L, KGBS-H, GASS, introversion scale, and CES-D were assessed with Pearson's correlation. Statistical significance was set at $\mathrm{p}=0.05$.

\section{RESULTS}

\section{Demographic characteristics}

There were no significant differences in terms of age, sex, education level, marital status, income/month, or job status between the four groups (Table 1).

\section{Comparison of playing patterns between the online} board gaming, ibGambling, and offGambling groups

The offGambling group spent more time per day gambling than the online board gaming group spent playing online board games and the ibGambling group spent gambling. The offGambling group also spent the most money on gaming or gambling, followed by the ibGambling and online board gaming groups, respectively (Table 1). The offGambling and ibGambling groups reported a much higher increase in bets than did the online board gaming group. Additionally, the offGambling and ibGambling groups had a more difficult time stopping gambling than did the online board gaming group. The offGambling group also experienced more problems relating to interpersonal relationships than did the ibGambling and online board gaming groups (Table 1).

Seventy percent of the members of the ibGambling group and $78 \%$ of those in the offGambling group played online board games. Meanwhile, $76 \%$ of the members of the offGambling group engaged in ibGambling, while 19\% of those in the online board gaming group engaged in ibGambling. Only $2 \%$ of the members of the online board gaming group and $6 \%$ of members of the ibGambling group engaged in offGambling (Table 1).

\section{Comparison of gambling tendency and psychological symptoms between the four groups}

Compared to the healthy comparison subjects, gambling abstinence self-efficacy was significantly lower in the online board gaming, ibGambling, and offGambling groups. However, there was no significant difference in GASS scores between these latter three groups (Table 2).

Regarding gambling behaviors, KGBS-L scores were higher in the online board gaming group than in the ibGambling and offGambling groups; however, KGBS-L scores were lower in the healthy comparison group than in both the gambling groups and the gaming group. Meanwhile, KGBS-H scores were higher in the offGambling group than in the online board gaming and ibGambling groups but, again, they were lowest among the healthy comparison subjects (Table 2).

Individuals in the gambling and gaming groups were more introverted than the healthy control subjects were, with those in the ibGambling group being more introverted than those in the online board gaming and offGambling groups were. Individuals in the two gambling groups and the gaming group were also more depressed than the healthy control subjects were, with those in the offGambling group being more depressed than those in the online board gaming and ibGambling groups. Those in the offGambling group also showed the most unstable mood compared to the healthy comparison subjects (Table 2). 
There were no significant differences regarding gambling tendency and psychological symptoms between individuals who only played online board games and individuals who engaged in both online board gaming and ibGambling. Further, there were no significant differences in the above variables between individuals who only engaged in offGambling and individuals who engaged in both online board gaming and offGambling. Finally, there were no significant differences in

Table 1. Comparison of demographic characteristics and gambling and gaming trends between the groups

\begin{tabular}{|c|c|c|c|c|c|}
\hline & Healthy control & Web board & ibGambling & OffGambling & Statistics \\
\hline Age & $35.2 \pm 7.2$ & $38.3 \pm 8.6$ & $36.9 \pm 9.1$ & $36.6 \pm 8.8$ & $\mathrm{~F}=1.2, \mathrm{p}=0.32$ \\
\hline Sex (male/female) & $80 / 20$ & $80 / 20$ & $80 / 20$ & $80 / 20$ & $\mathrm{~F}<0.01, \mathrm{p}<1.00$ \\
\hline Marital status (single/married) & $57 / 43$ & $56 / 44$ & $53 / 47$ & $47 / 51$ & $\chi^{2}=1.9, p=0.58$ \\
\hline Education & & & & & $\chi^{2}=10.4, p=0.11$ \\
\hline Less than high school & 13 & 12 & 7 & 8 & \\
\hline College/university & 74 & 75 & 76 & 82 & \\
\hline Master/PhD & 13 & 13 & 17 & 10 & \\
\hline Income & & & & & $\chi^{2}=5.2, p=0.52$ \\
\hline Less than $\$ 3000 /$ month & 21 & 18 & 23 & 13 & \\
\hline$\$ 3,000-6,000 /$ month & 46 & 50 & 51 & 57 & \\
\hline More than $\$ 6,000$ & 33 & 32 & 26 & 31 & \\
\hline Job (job/no-job) & $88 / 12$ & $87 / 13$ & $91 / 9$ & $91 / 9$ & $\chi^{2}=1.3, p=0.72$ \\
\hline Students & 6 & 4 & 5 & 10 & \\
\hline Officers & 65 & 65 & 72 & 60 & \\
\hline Service & 9 & 9 & 10 & 5 & \\
\hline Professions/management & 8 & 9 & 4 & 16 & \\
\hline No job & 12 & 13 & 9 & 9 & \\
\hline Playing time (hour/day) & - & $2.1 \pm 1.5$ & $2.4 \pm 1.7$ & $3.8 \pm 1.9$ & $\mathrm{~F}=16.8, \mathrm{p}<0.01^{\mathrm{a}}$ \\
\hline Money spent (\$/week) & - & $93.3 \pm 40.6$ & $529.3 \pm 300.6$ & $1271.4 \pm 249.7$ & $\mathrm{~F}=6.1, \mathrm{p}<0.01^{\mathrm{b}}$ \\
\hline Money increase (yes/no) & - & $55 / 45$ & $72 / 28$ & $87 / 13$ & $\chi^{2}=25.1, p<0.01^{c}$ \\
\hline Stop failure (yes/no) & - & $56 / 44$ & $74 / 26$ & $87 / 13$ & $\chi^{2}=24.2, \mathrm{p}<0.01^{\mathrm{d}}$ \\
\hline Problem IPR (yes/no) & - & $27 / 73$ & $30 / 70$ & $51 / 49$ & $\chi^{2}=14.8, \mathrm{p}<0.01^{\mathrm{e}}$ \\
\hline Web board use (yes/no) & $0 / 100$ & $100 / 0$ & $70 / 30$ & $78 / 22$ & $\chi^{2}=33.7, p<0.01^{\mathrm{f}}$ \\
\hline Everyday/week & 0 & 60 & 41 & 40 & \\
\hline 4-6 days/week & 0 & 40 & 23 & 17 & \\
\hline Less than 3 days/week & 0 & 0 & 6 & 21 & \\
\hline No use & 100 & 0 & 30 & 22 & \\
\hline ibGambling use (yes/no) & $0 / 100$ & $19 / 71$ & $100 / 0$ & $76 / 24$ & $\chi^{2}=139.1, p<0.01^{g}$ \\
\hline Everyday/week & 0 & 0 & 46 & 26 & \\
\hline 4-6 days/week & 0 & 1 & 54 & 24 & \\
\hline Less than 3 days/week & 0 & 18 & 0 & 26 & \\
\hline No use & 100 & 71 & 0 & 24 & \\
\hline OffGambling use (yes/no) & $0 / 100$ & $2 / 98$ & $6 / 94$ & $100 / 0$ & $\chi^{2}=267.0, \mathrm{p}<0.01^{\mathrm{h}}$ \\
\hline Everyday/week & 0 & 0 & 0 & 15 & \\
\hline 4-6 days/week & 0 & 0 & 0 & 10 & \\
\hline Less than 3 days/week & 0 & 2 & 6 & 75 & \\
\hline No use & 100 & 98 & 94 & 0 & \\
\hline
\end{tabular}

Problem IPR: problems in interpersonal relationship, ibGambling: internet-based gambling, OffGambling: offline gambling, Post hoc test, a: Web board=ibGambling <Offgambling, b: Web board $<$ ibGambling $<$ Offgambling, $\mathrm{c}$ : Web board $<$ ibGambling=Offgambling, $\mathrm{d}$ : Web board $<$ ibGambling=Offgambling, e: Web board=ibGambling<Offgambling, f: ibGambling=Offgambling<Web board, g: Web board<Offgambling $<$ ibGambling, h: Web board=ibGambling<Offgambling 
Table 2. Comparison of gambling tendency and psychological symptoms between the groups

\begin{tabular}{lccccc}
\hline & Healthy control & Web board & ibGambling & OffGambling & Statistics \\
\hline GASS & $79.8 \pm 16.8$ & $48.4 \pm 18.0$ & $53.3 \pm 21.6$ & $49.2 \pm 16.9$ & $\mathrm{~F}=24.5, \mathrm{p}<0.01^{\mathrm{a}}$ \\
KGBS & & & & \\
$\quad$ KGBS-L & $13.1 \pm 2.9$ & $19.7 \pm 4.1$ & $17.9 \pm 6.9$ & $17.9 \pm 4.3$ & $\mathrm{~F}=15.4, \mathrm{p}=0.012^{\mathrm{b}}$ \\
KGBS-H & $1.5 \pm 3.3$ & $12.3 \pm 6.2$ & $13.4 \pm 7.7$ & $17.6 \pm 5.6$ & $\mathrm{~F}=51.1, \mathrm{p}<0.01^{\mathrm{c}}$ \\
Introverted & $12.4 \pm 6.7$ & $16.3 \pm 7.8$ & $18.3 \pm 6.4$ & $16.3 \pm 7.8$ & $\mathrm{~F}=8.3, \mathrm{p}<0.01^{\mathrm{d}}$ \\
CES-D & $13.3 \pm 8.8$ & $22.1 \pm 8.3$ & $21.7 \pm 8.9$ & $27.3 \pm 7.7$ & $\mathrm{~F}=23.7, \mathrm{p}<0.01^{\mathrm{e}}$ \\
Mania & $7.5 \pm 3.6$ & $9.4 \pm 4.2$ & $9.1 \pm 4.0$ & $10.5 \pm 3.6$ & $\mathrm{~F}=5.0, \mathrm{p}=0.03^{\mathrm{f}}$ \\
\hline
\end{tabular}

GASS: Gambling abstinence self-efficacy scale, KGBS: Korean Gambling Behavior Scale, CES-D: Center for Epidemiologic Studies-depression Scale, a: healthy control<web board=ibGambling=OffGambling, b: healthy control<ibGambling=OffGambling<web board, c: healthy control<web board=ibGambling $<$ OffGambling, d: healthy control< $<$ web board=OffGambling $<$ ibGambling, e: healthy control $<$ web board= ibGambling<OffGambling, f: healthy control<OffGambling

these variables between individuals who only engaged in offGambling and individuals who engaged in both ibGambling and offGambling.

There were no significant correlations between scores on the KGBS-L, KGBS-H, GASS, introversion scale, and CES-D across participants. However, KGBS-L scores were negatively correlated with introversion scale scores $(\mathrm{r}=-0.41, \mathrm{p}<0.01)$ and CES$\mathrm{D}$ scores $(\mathrm{r}=-0.39, \mathrm{p}<0.01)$ in the online board gaming group. There were no significant correlations between the KGBS-L, KGBS-H, GASS, introversion scale, and CES-D scores in other sub-groups (ibGamblers and OffGamblers group).

\section{DISCUSSION}

To the best of our knowledge, the current study is the first to compare the characteristics of online board game users with those of online and offline gamblers. According to our results, online board gamers have positive reasons for gaming, with our respondents in this group exhibiting higher KGBS-L scores than individuals who engaged in ibGambling and offGambling. Further, such gamers also exhibit less risky behaviors, with our respondents reporting lower KGBS-H scores than the offGamblers. Additionally, online board gamers are less introverted than ibGamblers and less depressed than offGamblers.

Regarding gambling patterns, in the current study, both types of gamblers (offline and online) showed more serious gambling-related problems than did the online board gamers, spending more money, increasing their bets more regularly, and experiencing more difficulty in stopping gambling. Interestingly, online board gaming shares similar characteristics with ibGambling, such as constant availability, easy access, increased privacy, and facilitation through an interactive, and immersive internet environment, all of which cannot be found in offline gambling. ${ }^{7,19}$ Despite these similarities, online board gamers showed less serious problematic gambling behaviors than ibGamblers.
Most ibGamblers (70\%) and offGamblers (78\%) played online board games, and $67 \%$ of offGamblers engaged in ibGambling. However, just 19\% of online board gamers engaged in ibGambling and only $2 \%$ of engaged in offGambling. We conjecture that gamblers may regard online board gaming as a gambling substitute, but that online board gamers do not consider gambling as an online board game substitute. These results contrast with those of some previous studies. ${ }^{20}$ In a review of related studies, Armstrong et al. suggested that youths who experience high exposure to simulated gambling games are prone to engaging in monetary gambling and developing gambling problems. ${ }^{20}$ The difference between Armstrong et al.s results and the present findings may be due to the participants' age (youth vs. adult) and the more detailed classification of gambling in our study (online board games vs. ibGambling vs. offGambling).

In our results, online board gamers showed higher KGBS-L scores and lower KGBS-H scores than did gamblers. This indicates that online board gamers have positive reasons for gaming and exhibit less risky gambling behaviors than do ibGamblers and offGamblers. Additionally, KGBS-L scores were negatively correlated with introversion scale scores $(\mathrm{r}=-0.41$, $\mathrm{p}<0.01)$ and CES-D scores $(\mathrm{r}=-0.39, \mathrm{p}<0.01)$ in the online board gaming group. These results may support those of Bailey et al.s electronic gambling machine study. ${ }^{21}$ Here, examining the mechanism of excitement and enjoyment caused by wins/losses in gambling, Bailey et al. ${ }^{21}$ reported that electronic gambling machines have positive effects on younger groups as a result of the associated general excitement, and positive effects for older groups through the prospect of financial gain. However, many studies on gambling have cautioned that simulated internet gambling can act as a gateway to the world of monetary gambling. ${ }^{22}$

Additionally, our study showed no significant difference in abstinence self-efficacy between online board gamers, ibGamblers, and offGamblers. This may be because the charac- 


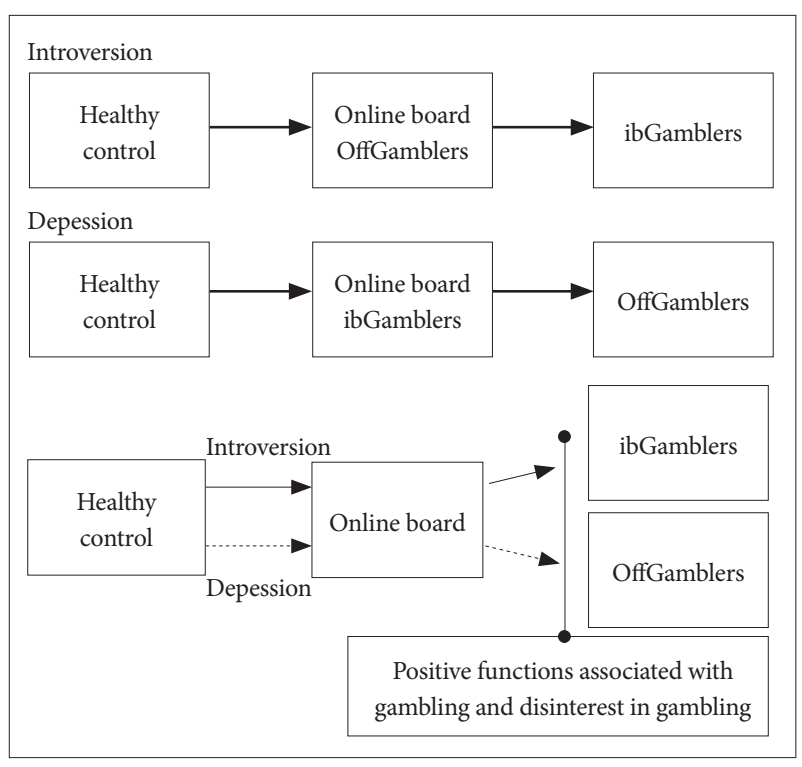

Figure 2. Effects of psychopathology on the gateway to gambling. ibGamblers: individuals who play Internet-based gambling, OffGamblers: individuals who play gambling on offline.

teristics of online board games include aspects of both ibGambling and offGambling. For example, 1) an online board game is a form of simulated gambling, and 2) it is played online, allowing gamers to play at home, affording a private playing environment, and omitting face-to-face interaction. ${ }^{2}$

Regarding psychopathology, the online board gamers in our study were less depressed than the offGamblers and were less introverted than the ibGamblers (Figure 2). These results may support Levesque et al. ${ }^{23}$ findings, which suggested that psychological vulnerability could aggravate the severity of gambling problems and cognitive distortion, but that outcomes can differ depending on the preferred gambling activity. ${ }^{23} \mathrm{Giv}$ en these previous findings, online board gamers may have less distorted cognition and a lower preference for gambling than do offGamblers. In our study ibGamblers were found to be the most introverted. OffGamblers and web board players were more introverted than healthy controls (Figure 2). We think that introversion could present in persons exhibiting gambling behaviors. The characteristics of individuals with gambling behaviors were reported to include a preference for a private playing environment, no face-to-face interaction, little verbal communication, and fewer consequences for lacking emotional control, as compared with offGambling. ${ }^{2}$ Taken together, as seen in our results pertaining to psychopathology, online board gaming could be a gateway to the world of gambling (ibGambling or OffGambling). However, the tendency to engage in gaming with positive intentions or disinterest in gambling in online board gamers would help prevent online board gaming to progress into online or offline gambling (Figure 2).

There are several limitations to the current study. First, be- cause the results of the online survey were based on a relatively small sample with a low response rate, readers should be cautious when generalizing the findings. Second, regarding the classification of the groups, the data of participants who overlapped between groups (e.g., ibGambling and offGambling, online board gambling and ibGambling) were not fully analyzed because of the small number of subjects; future research should focus on overlapping groups. Finally, the current study was only based on self-report measures, without using objective assessment tools. As a result of this limitation, the healthy comparison group could not be validated completely.

Based on our results, given the positive intentions for gaming and less risky gambling behaviors of online board gamers, online board games could constitute a beneficial replacement for gambling. Additionally, we cautiously suggest that problematic gambling behaviors are induced not by the interface (online board games, ibGambling, or offGambling) but by users' characteristics and psychopathology. However, online board users should be cautious about migrating to the world of monetary gambling.

\section{Acknowledgments}

This work was supported by Game User Care Center, Korea.

\section{REFERENCES}

1. Markey K, Swanson F, Jenkins A, Jennings BJ, St. Jean B, Rosenberg V, et al. The effectiveness of a web-based board game for teaching undergraduate students information literacy concepts and skills. D-Lib Mag $2008 ; 14$.

2. Eroukmanoff V, Costes JM, Tovar ML. Poker Players, a Population with a Particular Profile? Paris: Observatory of games; 2014.

3. Wood RT, Williams RJ, Lawton PK. Why do Internet gamblers prefer online versus land-based venues? Some preliminary findings and implications. J Gambl Issues 2007;20:235-252.

4. McCormack A, Griffiths MD. A scoping study of the structural and situational characteristics of Internet gambling. Int J Cyber Behav Psychol Learn 2013;3:29-49.

5. Gainsbury SM, Suhonen N, Saastamoinen J. Chasing losses in online poker and casino games: Characteristics and game play of Internet gamblers at risk of disordered gambling. Psychiatry Res 2014;217:220-225.

6. Moreau A, Chabrol H, Chauchard E. Psychopathology of online poker players: review of literature. J Behav Addict 2016;5:155-168.

7. Monaghan S. Responsible gambling strategies for Internet gambling: the theoretical and empirical base of using pop-up messages to encourage self-awareness. Comput Hum Behav 2009;25:202-207.

8. De Luigi N, Gibertoni D, Randon E, Scorcu AE. Patterns of gambling activities and gambling problems among Italian high school students: Results from a latent class analysis. J Gambl Stud 2018;34:339-359.

9. Jauregui P, Estevez A, Urbiola I. Pathological gambling and associated drug and alcohol abuse, emotion regulation, and anxious-depressive symptomatology. J Behav Addict 2016;5:251-260.

10. Chen YF, Peng SS. University students' Internet use and its relationships with academic performance, interpersonal relationships, psychosocial adjustment, and self-evaluation. Cyberpsychol Behav 2008;11: 467-469.

11. Pantic I. Online social networking and mental health. Cyberpsychol Behav Soc Netw 2014;17:652-657.

12. National Gaming Control Commission (NGC). Available at: http:// 
www.ngcc.go.kr/Download. Accessed August 17, 2018.

13. Lee SM, Kim GH, Choi YS, Le HP, Kim JN, Kim SJ, et al. Development of Korean Gambling Behavior Scale-H: A scale for inquiry of problematic gambling. Korean J Psychol Gen 2011;30:1053-1082.

14. David H, Nicole P, Karyn M. Self-efficacy in pathological gambling treatment outcome: development of a gambling abstinence self-efficacy scale (GASS). Int Gambl Stud 2004;4:99-108.

15. Radloff LS. The CES-D scale a self-report depression scale for research in the general population. Appl Psychol Meas 1977;1:385-401.

16. Cho S, Cho Y. Depressive symptoms following natural disaster in Korea: Psychometric properties of the Center for Epidemiologic Studies Depression Scale. Health Qual Life Outcomes 2017;15:230.

17. Smarr KL, Keefer AL. Measures of depression and depressive symptoms: Beck Depression Inventory-II (BDI-II), Center for Epidemiologic Studies Depression Scale (CES-D), Geriatric Depression Scale (GDS), Hospital Anxiety and Depression Scale (HADS), and Patient Health Questionnaire-9 (PHQ-9). Arthritis Care Res (Hoboken) 2011;63 (Suppl 11):S454-S466.
18. McDowell I. Measuring Health: A Guide to Rating Scales and Questionnaires. Oxford: Oxford University Press; 2006.

19. Gainsbury S, Parke J, Suhonen N. Attitudes towards Internet gambling: perceptions of responsible gambling, consumer protection, and regulation of gambling sites. Comput Hum Behav 2013;29:235-245.

20. Armstrong T, Rockloff M, Browne M, Li E. An exploration of how simulated gambling games may promote gambling with money. J Gambl Stud 2018;34:1165-1184.

21. Bailey PE, Gonsalvez CJ, Maiuolo M, Leon T, Benedek G. The age-related positivity effect in electronic gambling. Exp Aging Res 2018;44:135147.

22. Hayer T, Kalke J, Meyer G, Brosowski T. Do simulated gambling activities predict gambling with real money during adolescence? Empirical findings from a longitudinal study. J Gambl Stud 2018;34:929-947.

23. Levesque D, Sevigny S, Giroux I Jacques C. Psychological vulnerability and problem gambling: the mediational role of cognitive distortions. J Gambl Stud 2018;34:807-822. 